\title{
Spatiotemporal patterns of urban thermal environment and comfort across 180 cities in summer under China's rapid urbanization
}

\author{
Zhibin Ren ${ }^{1}$, Yao Fu ${ }^{1}$, Yunxia Du ${ }^{\text {Corresp., }}{ }^{1}$, Hongbo Zhao ${ }^{\text {Corresp. } 2}$ \\ ${ }^{1}$ Key Laboratory of Wetland Ecology and Environment, Northeast Institute of Geography and Agroecology,Chinese Academy of Sciences, Changchun, \\ China \\ ${ }^{2}$ Key Research Institute of Yellow River Civilization and Sustainable Development \& Collaborative Innovation Center on Yellow River Civilization of Henan \\ Province, Henan University, Kaifeng, China \\ Corresponding Authors: Yunxia Du, Hongbo Zhao \\ Email address: duyunxia@iga.ac.cn, 10340024@vip.henu.edu.cn
}

Background. China is considered as the largest and most rapidly urbanizing nation in the world. However, possible changes of urban thermal environment and comfort under the rapid urbanization in China still remain poorly understood at a national scale.

Methods. Based on the data collected from 180 cities in 1990, 2005, and 2015 in China, the spatiotemporal patterns of urban thermal environment and comfort in summer and their relationships with urbanization variables were investigated in this study.

Results. Our results indicate that urban thermal environment has changed greatly during the 25 years. Furthermore, the changes of urban climate in different regions are inconsistent. The Physiological Equivalent Temperature( PET) at most cities (81\%) in China increased from 1990 to 2015, which suggested that urban thermal comfort in China was also deteriorating during the 25 years .

However, while the PET of some cities in China began to decrease from 2005 to 2015, there were still 33\% of cities that had positive trends, which mainly located in North region. Urbanization resulted in a significant influence on urban climate. Compared to southern cities, northern cities were more sensitive to urbanization impact. The most important contribution to increasing of PET for urbanization variables is Gross Domestic Product, followed by urban population. The analysis results reveal changing patterns of urban thermal comfort in China during summer season. It can help urban government and managers improve urban thermal environment and comfort. 


\section{Highlights}

2 - Urban thermal environment and comfort has changed greatly during the last 25 years and 3 such changes in different regions were inconsistent.

4 - From 1990 to 2015, the Physiological Equivalent Temperature (PET) of most cities (81\%) in

5 China exhibited an increasing trend, especially in North region $\left(4^{\circ} \mathrm{C}\right)$, followed by Northeast

6 region $\left(3.4^{\circ} \mathrm{C}\right)$.

7 - From 2005 to 2015, the PET of some cities in China began to exhibit a decreasing trend.

8 However, there were still $33 \%$ of cities, which exhibited positive trends and mainly located in

9 North region.

10 - Urbanization has a significant influence on urban climate and the most important

11 contribution to changes in urban thermal comfort is gross domestic product, followed by urban

12 population.

- Our results reveal the spatiotemporal changing patterns of urban thermal comfort and can help urban planner to improve urban thermal environment in China. 

comfort across 180 cities in summer under China's rapid urbanization Agroecology, Chinese Academy of Sciences, Changchun 130102, China

${ }^{2}$ Key Research Institute of Yellow River Civilization and Sustainable Development \& Collaborative

*Corresponding author: Tel:+86 431 85542321;Fax:+86 43185542298 


\section{Abstract:}

53 Background. China is considered as the largest and most rapidly urbanizing nation in the world.

54 However, possible changes of urban thermal environment and comfort under the rapid

55 urbanization in China still remain poorly understood at a national scale.

56 Methods. Based on the data collected from 180 cities in 1990, 2005, and 2015 in China, the

57 spatiotemporal patterns of urban thermal environment and comfort in summer and their relationships with urbanization variables were investigated in this study.

Results. Our results indicate that urban thermal environment has changed greatly duringthe 25

60 years. Furthermore, the changes of urban climate in different regions are inconsistent. The

61 Physiological Equivalent Temperature( PET) at most cities (81\%) in China increased from 1990

62 to 2015, which suggested thaturban thermal comfort in China was also deteriorating during the

6325 years. However, while the PET of some cities in China began to decrease from 2005 to 2015,

64 there were still $33 \%$ of cities that had positive trends, which mainly located in North region.

65 Urbanization resulted in a significant influence on urban climate. Compared to southern cities, 66 northern cities were more sensitive to urbanization impact. The most important contribution to 67 increasing of PET for urbanization variables is Gross Domestic Product, followed by urban 68 population. The analysis results reveal changing patterns of urban thermal comfort in China

69 during summer season. It can help urban government and managers improve urban thermal 70 environment and comfort 
Key words: Urban Climate; Physiological Equivalent Temperature (PET); Thermal comfort; Urbanization

\section{Introduction}

Many parts in the world have experienced the rapid urbanization during last few decades (Montgomery,2017; Szabo, 2018). The expansion of urban impervious surfaces can especially change urban thermal environment, which makes significant impacts on urban life quality and even urban sustainable development (Cao et al.,2018; Lin et al.,2018). The high urban temperature and intensive heat can result in high cooling energy consumption (Giridharan et al.,2018; Kolokotroni et al.,2007), raise pollution levels (Sarrat et al.,2006; Weng and Yang,2006), reduce urban thermal comfort (UTC)( Basu and Samet,2002; Klenk et al.,2010; Salata et al., 2014), decrease outdoor activities and cause serious public health problems (Wong et al.,2018; Sagris et al.,2018). The urban thermal environment may be expected to become worse in the coming years with two significant escalating global trends (urban heat islands(UHI) and global warming). Therefore, a thorough understanding of urban thermal environmental patterns is critical for urban planners to adapt effective mitigation measures and strategies to improve urban thermal environment, especially in summer time.

Urban thermal environmental issues have recognized by scientists and urban planners during the past several decades. Previous studies on the urban thermal environment have relied on land surface temperature extracted from remote sensing (e.g., Weng et al.,2007; Cao et al.,2010; Lin, 2018) and air temperature observed at weather station (e.g., Shereif et al., 2018; Oxoli et al., 2018; Wang et al., 2018). The urban temperature has been the most intuitive performance indicator for analyzing the urban thermal environment (Lan et al.,2017; Moustris et al.,2018). However, the urban air temperature is an inadequate measure to investigate urban thermal environment (Aljawabra et al.,2018; Cheung et al.,2018). Moreover, urban thermal 
96 comfort is a state of mind that articulates satisfaction with a specific urban thermal environment,

97 depending on a combined effect of the physical and climatic parameters(Aljawabra et al.,2018;

98 Galagoda et al.,2018). When analyzing the urban thermal environment, it is important to bear in

99 mind that the other factors could also influence urban thermal environment such as solar

100 radiation, humidity, and wind speed besides the air temperature(Lee et al.,2018; Yang et al.,2018

101 ). Therefore, the urban thermal comfort can better render the implication of the urban thermal

102 environment because it considers an integral effect of climatic parameters, such as, air

103 temperature, wind speed, air humidity and solar radiation (Salata et al.,2017). When urban

104 residents are under more thermal stress, an urban accompanying discomfort could negatively

105 affect their outdoor life and health in many ways (Salata et al.,2017;Cao et al.,2018 ). Therefore,

106 a better understanding and monitoring of the urban thermal comfort is necessary and important

107 for developing strategies for urban planners, and policy makers to mitigate urban thermal stress

108 and improve urban life quality in cities.

109 China as a developing country has experienced a rapid urbanization in the past six decades.

110 In China, some studies showed that urbanization has contributed greatly to the observed warming

111 since the 1960s (Tarabon et al.,2018; Wang et al., 2019). By 2030, urban dwellers in China will

112 increase by nearly 200 million (Wu et al., 2014), which will further exacerbate urban warming

113 stress on humans. However, how the urban thermal comfort changes in China under the rapid

114 urbanization is not well understood yet. Furthermore, most previous efforts about urban thermal

115 comfort just focused on several selected measurements by using conventional meteorological

116 monitoring approaches in a single city or a few big cities (e.g., Lindén et al.,2016; Cheung et

117 al.,2018; Xu et al.,2018). This may not only understand the thermal comfort in single cities, but

118 also fail to reveal the detailed patterns of urban thermal comfort at a national scale (Huang et

119 al.,2016; Zhou et al., 2018). Spatiotemporal patterns of urban thermal comfort under the rapid

120 urbanization in China are still poorly understood at the national scale. Therefore, more detailed

121 studies on nationwide cities and across different climatic zones are needed. The better

122 understanding of spatiotemporal change of urban thermal comfort is imperative today especially 
123

124

125

126

127

128

130

131

132

133

134

135

136

137

138

139

140

141

142

143

144

145

146

when China is constrained by both urbanization and global climate change.

In this study, based on long-term daily meteorological observations and urbanization information collected from the Statistics Yearbook of Cities in 1990, 2005, to 2015 in 180 cities of China, we propose to analyze spatiotemporal patterns of urban thermal environment and comfort in the cities. More specific research objectives include: (1) to investigate spatiotemporal changes of urban climate under a rapid urbanization in 1990, 2005 and 2015, (2) to explore the spatiotemporal changes of urban thermal comfort in the 180 cities in summer under the rapid urbanization, and (3) to analyze relationships between thermal comfort index and urbanization factors. The expected research results would be helpful for better understanding of relationships between urbanization and urban thermal comfort and provide useful information to urban government and planner to improve urban thermal environment.

\section{Methods}

\subsection{Study areas}

In our study, the 180 cities under rapidly urbanizing process were selected due to the availability of relevant meteorological and urbanization data in China (Fig.1). The administrative boundary of cities in China often includes very large areas of countryside. In this study, only the built-up area of each city was analyzed, without considering the whole area within the administrative boundary. The built-up area refers to the urbanized area of a city (National Bureau of Statistics of China, 1990-2010). In order to explore regional patterns in urban thermal environment, the selected cities in our study were then divided into seven different regions (Northeast, North, South, Northwest, Southwest, Central and East), according to regional division criterion used by the national government(Zhao et al.,2013). These seven regions include all the provinces of mainland China.

|Insert Fig. 1 around here| 


\subsection{Data collection}

Meteorological data: Given the long-term meteorological observation data from 1980 to2016, we found that there were not extreme climatic events occurring in years 1990, 2005 and 2015 and the climate in 1990, 2005, and 2015 could almost represent the average climatic condition of 1990s, 2000s, and 2010s (Table.1). Therefore, the historical publicly available meteorological data observed in 1990, 2005 and 2015 from the National Meteorological Information Center (http://data.cma.cn/) were used in our study in order to investigate spatiotemporal trends of urban thermal comfort. The monthly meteorological parameters observed in summer months (June, July and August) used in this study included monthly average values of air temperature, relative humidity, wind velocity and global radiation. For every city, all meteorological parameters observed from all the Chinese surface meteorological stations in urban built-up area were used in our study and such kind of data has been widely used to study the urban thermal environment (e.g., Han et al.,2019; Liu et al., 2019; Yang et al., 2019). The four variables from the meteorological stations in June, July and August were also averaged into the summer season. Our focus is on the summer season because hundreds of millions of urban residents in China endure their highest heat-related stress during the time period of a year. Urbanizaiton data: all the data of urbanization variables were collected from the Statistics Yearbook of Cities in China (National Bureau of Statistics of China, 1990-2016). This series of yearbooks has been compiled and published annually by the National Bureau of Statistics since 1985. The document data published in each yearbook in a given year were from the previous year. The yearbooks published between 1991 and 2016 were used to collect data for the 25 years between 1990 and 2015. Urbanization is a process marked by urban area expansion with intensive land use change, economic development, and rapid population growth (Antrop, 2000; Weber and Puissant, 2003). Therefore, all the continuously recorded variables related to population, land cover and economic development were used to analyze urbanization impact on urban thermal environment in our study. There were six variables that were defined or calculated according to the official statistical yearbooks(National Bureau of Statistics of China, 
174

175

176

177

178

179

180

181

182

183

184

185

186

187

188

189

190

191

192

193

194

195

196

197

198

199

1991-2016), including total urban population, urban population in build-up area, built-up $\operatorname{area}\left(\mathrm{km}^{2}\right)$, population density $\left(\mathrm{n} / \mathrm{km}^{2}\right), \operatorname{GDP}\left(10^{8}\right.$ Yuan $)$, per capita GDP(Yuan/person) and urban vegetation coverage (\%).

\subsection{Calculation of Urban thermal comfort}

Physiological Equivalent Temperature (PET) is one of the most regularly used thermal comfort index to assess the human thermal condition, which has been widely applied in different climatic zones (Potchter et al. 2018). PET is based on human energybalance in terms of the Munich Energy Balance Model for individuals (Matzarakis et al.2013). It is a universal index which integrates the thermo-physiology of the human body (sex, height, activity, clothing resistance for heat transfer,shortwave albedo and long wave emissivity of the surface) and the multiple relevant meteorological parameters including air temperature, relative humid, wind velocity etc. $\quad$ PET is derived from the human energy balance and expressed in the unit $\left({ }^{\circ} \mathrm{C}\right)$ as an indicator of thermal stress, which makes the result more comprehensible for urban and regional planners, decision-makers, and even the public (Froehlich et al.2018). Based on the monthly average values of air temperature, relative humidity, wind velocity and global radiation for summer in 1990, 2005, and 2015 in this study, the monthly PET index for urban stations for every city in June, July and August was calculated by RayMan software (Matzarakis et al. 2007, 2010). The thermos-physiological parameters of the human beings used in this research were set up as a typical male 35 years old, $1.75 \mathrm{~m}$ height, $75 \mathrm{~kg}$ weight, with an internal heat production of $80 \mathrm{~W}$ and a heat transfer resistance of the clothing of 0.9 clo. The assessment scale used in this study to classify cold stress $(\mathrm{PET}<13 \circ \mathrm{C})$, thermal comfort $(13 \leqslant \mathrm{PET} \leqslant 29)$ and heat stress $(\mathrm{PET}>35 \circ \mathrm{C})$ is described in Table 2 .

|Insert Table 2 around here|

\subsection{Data analysis}

The values of the PET in June, July and August for urban stations in each city were first averaged into a summer PET for all following analyse. Based on the values of summer PET in 
200

201

202

203

204

205

206

207

208

209

210

211

212

213

214

215

216

217

218

219

220

221

222

223

224

1990, 2005, and 2015, spatial change patterns of PET among the three years in different regions in China were then conducted in our study.

By analyzing the distribution of urbanization variables, we found that that GDP, per capita GDP, built-up area, total population, population density, population in the built-up area had a highly skewed distribution. Therefore, these variables were in-transformed before correlation and regression analyse in order to improve the comparability and the linearity of relationships between PET and a set of urbanization variables. In order to analyze the impact of urbanization on PET, the research on the relationship between PET and urbanization variables was conducted. First, the Pearson correlation analysis and correlation coefficient were conducted between these independent and dependent variables. Second, a simple linear regression model was used to determine the effect of urbanization on PET. In our analysis, these six urbanization variables in the selected three years $(1990,2005$, and2015) were used as independent variables and the corresponding average PET was used as a dependent variable. As most variables were significantly correlated with each other, we finally conducted a multiple regression analysis in which PET was the response variable and urbanization variables were predictors. All statistical analyses were carried out by using SPSS19.0.

\section{Results}

\subsection{Spatiotemporal changes of urbanization and meteorological parameters in China}

Per the seven variables of urbanization in China, the statistical results showed that China experienced a rapid urbanization during the last 25 years (1990-2015) (Table.3). Compared to $45.4 \mathrm{~km}^{2}$ in 1990, the mean urban build-up area reached to $117.9 \mathrm{~km}^{2}$ and $160.2 \mathrm{~km}^{2}$ in 2005 and 2015 respectively. Urban population and GDP increased greatly from 1990, 2005 to 2015. During the last 25 years, urban vegetation coverage also increased sharply (Table.3).

|Insert Table 3 around here|

Due to the rapid progress of urbanization such as land cover change and the increasement of 
225 urban population over China, urban thermal parameters, such as, air temperature, humidity, wind

226 speed, solar radiation parameters could correspondingly be changed correspondingly. The

227 average air temperature increased significantly from 1990 to 2005 and decreased slightly from

2282005 to 2015 (Table 3). Analysis of the average value of air temperature in different regions

229 (Fig.2) indicated that different changes have occurred across different regions from 1990 to 2015.

230 The air temperature in Northeast and Northwest increased gradually from 1900, 2005 to 2015.

231 However, it decreased from 1990 to 2015 in Central and East China. The relative humidity and

232 wind speed showed significant decreasing changes, especially in Northeast, North, and

233 Northwest regions.

234 |Insert Fig. 2 around here|

235

236

237

238

239

240

241

242

243

244

245

246

247

248

249

\subsection{Spatiotemporal changes of PET across 180 cities in hot summer}

The average PET increased significantly from 1990 to 2015(Table 4), which means people suffer from more and more heat stress during the summer period and feel extremely uncomfortable. For the 180 cities in 1990 , the PET ranged from $13.2^{\circ} \mathrm{C}$ to $34.3^{\circ} \mathrm{C}$ with an average of $28.7^{\circ} \mathrm{C}$. The urban average PET reached up to $31.7^{\circ} \mathrm{C}$ with an increase rate of $11 \%$ from 1990 to 2005. Compared to the average PET in 2005, it slightly decreased in 2015 with the average value of $30.6^{\circ} \mathrm{C}$. Analysis of the average value of PET in all different regions in mainland China showed that cities in the South region had the highest level of PET with $33.5^{\circ} \mathrm{C}$, followed by the Central region. The lowest levels of PET have occurred in Northeast and Northwest region with only $27^{\circ} \mathrm{C}$ (Fig. 3). The frequency analysis of PET in 180 cities (Fig .4) indicated showed that the highest frequency for PET between 29 and 35 was $60 \%$ (Moderate heat stress) in 1990 and it increased gradually to $63 \%$ in 2005 , and $70 \%$ in 2015 . Meanwhile, the frequency for PET between 18 and 23 (No thermal stress) decreased gradually from 8\% in 1990 to $0.55 \%$ in 2015 .

|Insert Table 4 and Figs. 3 \& 4 around here| 
From 1990 to 2005, the PET of most cities in China exhibited an increasing change (Fig. 5-6).

251

252

253

254

255

256

257

258

259

260

261

262

263

264

265

266

267

268

269

270

271

272

273

Of the 180 cities investigated, ninety-five percent of them had positive change values, ranging from $0.1^{\circ} \mathrm{C}$ to $6.8^{\circ} \mathrm{C}$ (Fig. 5-6) and $80 \%$ of the values were larger than $1.5^{\circ} \mathrm{C}$, with a highest rate of increase occurring in North region $\left(4^{\circ} \mathrm{C}\right)$, followed by Northeast region $\left(3.4^{\circ} \mathrm{C}\right)$. From 2005 to 2015, the PET in some cities in China began to exhibit a decreasing change (Fig. 6). Sixty-seven percent had negative change values, especially in South region. However, there are still 33\% of cities had positive values ,mainly located in North region (Fig. 6-7). Overall, the PET of most cities (81\%) in China exhibited an increasing change (Fig. 6-7) from 1990 to 2015. |Insert Figs. 5 - 7 around here|

\subsection{Effect of urbanization on PET in hot summer in China}

Table 5 lists the Pearson's correlations between PET and urbanization variables. Five of the seven urbanization variables had significant positive effects on PET except for population density. Meanwhile, urban vegetation coverage had a negative relationship with PET. In addition, the increase 1 in $\operatorname{Ln}(\mathrm{GDP})$ resulted in an increase of 0.67 for PET (Fig. 7). The increase 1 in $\mathrm{Ln}$ (total population) lead to an increase of 0.61 for PET. From the $\mathrm{R}^{2}$ value in Fig 7 , we can easily see that the variables of GDP and total population could explain $22.0 \%$ and $13.2 \%$ of variance of PET, respectively. Finally the multiple regression analysis showed a constructed model using the four most significant variables as follows:

$\mathrm{y}=-25.759+\ldots 1.256 \mathrm{~b}_{1}-2.036 \mathrm{~b}_{2}+1.104 \mathrm{~b}_{3}+0.051 \mathrm{~b}_{4}$

where $\mathrm{y}$ is the green space coverage and b1-4 are the variables shown in Table 6. This model explained $31.6 .7 \%$ of the variance of PET.

|Insert Tables $5 \& 6$ around here|

\section{Discussion}

China has experienced the rapid urbanization during the last 30 years (Jiang et al.,2019; Lu

Peer) reviewing PDF | (2019:04:36787:1:2:NEW 21 Jun 2019) 
274 et al.,2019), which could definitely cause changes of urban climate. The warming change 275 caused by urbanization has already been well-documented (e.g., Lin et al.,2018; Fu et al.,2018;

276 Yang et al.,2019). Our results have also agreed to those existing studies, which showed that the

277 average air temperature increased significantly from 1990 to 2005 and to 2015. Such increasing

278 changes may be linked to appearances of increasing impervious surfaces during the rapid

279 urbanization progress. The greater absorption capacity of solar radiation, heat capacity and

280 conductivity in the urban area, resulted in more heat storage (Zhang et.al, 2019), which leads to a

281 substantial increase in sensible heat flux during daytime and heat release at night. Our studies

282 also demonstrated showed that the relative humidity appeared the significant decreasing

283 changes, which might be caused by huge losses of leaf area index, green vegetation fraction, and

284 so on because of urban sprawl and land use and land cover change) (LULC) (Hernandez-Moreno

285 et al.,2018; Sun et al.,2018). In addition,the mean wind speed for 180 cities also showed

286 significant decreasing changes from 1990 to 2005, and to 2015. The surface roughness over

287 urban region was significantly altered because of the emergence of high-rise buildings and other

288 LULCC(Walker,2011; Anup et al.,2019), which caused surface drag force increases and then

289 decreased the wind speed in cities.

290 In recent years, many studies have only used single-climate parameters, such as, air temperature (Ta), to serve as indicators of urban thermal environment (Weng et al.,2007; Shereif

292 et al., 2018; Oxoli et al., 2018). In fact, the temperature factor only could not represent

293 adequately urban thermal environment. Urban thermal comfort could better represent urban

294 thermal environment because of consideration of the integral effect of the climatic parameters of 295 the air temperature, wind speed, air humidity and solar radiation (Salata et al.,2017). Our results 296 indicated that the PET of most cities (81\%) in China exhibited a great increasing change (Fig. 3297 4) from 1990 to 2015 . The impact of urbanization on temperature and thermal comfort is quite 298 different among the different cities and regions in China. Our research also indicated that the 299 PET changes were much larger than air temperature changes associated with urban thermal 300 conditions. This is because that urbanization has a negative impact on relative humid and wind 
301 velocity in urban area in addition to the warming change. Therefore, thermal comfort should be a

302

303

304

305

306

307

308

309

310

311

312

313

314

315

316

317

318

319

320

321

322

323

324

325

326

327 better indicators to characterize the urban thermal environment than the urban air temperature.

In addition, our results also showed that cities in the South region had the highest level of PET (33.5), followed by the Central region and Northeast and Northwest region with only $27^{\circ} \mathrm{C}$ (Fig. 3), which could be closely linked with the different regional climates. Many studies found that the higher temperature and humidity over China during summer is mainly distributed in the southeast of China, and relatively lower temperature and humidity concentrates in the western and northern of China, which may cause the different regional patterns of PET (e.g., Li and Zha.,2018; Yao et al.,2017; Peng et al.,2018). Our results furtherly indicated that the change of PET also exhibits a regional characteristic, suggesting larger increasing trends occurring in Northeast and North China from 1990 to 2005, and to 2015 and some decreasing trends in South regional cities from 2005 to 2015 (Fig. 5-6). There may be several reasons for the spatial inconsistent changes of urban thermal comfort in these cities, which maybe closely related with the different processes of urbanization in different regions in China. The economic development in the north is dominated by heavy industries characterized with high energy consumption (Zhang et al.,2019; Pan et al.,2019). The average summer temperatures in Northeast and North regions could be increased greatly by waste heat released by secondary industry. Therefore, PET in the cold northeastern China is more susceptible to the impact of urbanization. However, the economic development in the south is dominated by light industries characterized with high technology(Wu et al.,2019; Liu et al.,2019). Many cities in South region have higher environmental efficiencies than those northeastern cities. Some regulations of reforming technology or other measures like recycling wastes intensively and subsidizing the sewage disposal plants in recent years play an important role in reducing emissions (Ma et al.,2019 ). Therefore, the PET increased slower in north regions from 1990 to 2005 and even decreased from 2005 to 2015 than that in south regions. It might also be because that China has put ecological civilization as a national strategy to build a beautiful China in recent years(Shi et al.,2019; Geall et al.,2018). This strategy became a great opportunity for urban forest 
328 development in China. The government strengthens the building of China's urban forest. Urban

329 forest amounts and quality also have been further improved, especially for south regions, which

330 has improved urban thermal environment to a certain extent (Liu et al.,2018).

331 Most of the previous studies analyzed relationships between urban air temperature and its 332 drivers across cities over time (Lin et al.,2018; Fu et al.,2018; Yang et al.,2019). The correlation 333 analyses between PET and associated drivers can be conducted across space and time(Yang et 334 al.,2019; Cao et al.,2018). In this study, we performed correlation analyses across both cities and 335 years, and a series of new and different findings were revealed. In this study, increased GDP and 336 population might be an important reason for the increased PET (Table 4-5). The increasing GDP 337 and population due to the urbanization might result in decreasing the vegetation coverage, and 338 increasing amounts of roads and buildings and energy consumption(Hernandez-Moreno et 339 al.,2018;Sun et al.,2019), and thus increasing the PET indirectly. The growing concentration of 340 GDP and population is the most basic connotation of urbanization, The secondary sector of the 341 economy for GDP includes that industries consume large quantities of energy and require 342 factories and machinery to convert the raw materials into goods and products and produce waste 343 heat that may cause thermal environmental problems(Wu et al.,2019; Zhang et al., 2019). 344 Besides, the heat generated by human body and people's daily life, such as, air conditions and 345 cars, has also caused the increasing artificial heat emissions (Liu et al.,2018; Ma et al.,2019; ) 346 and thereby affected people's thermal comfort. Our results indicated that the correlation between 347 urban vegetation coverage and PET is not significant. However, many previous studies 348 demonstrated that vegetation coverage has a remarkable impact on regional climate (e.g., Zhao et 349 al.,2014; Alo et al.,2010; Chen et al.,2017). It might be because that urban vegetation was 350 scattered and heterogeneous, surrounded by many impervious surfaces, which could reduce the 351 ecological function of vegetation, such as, decreasing temperature and increasing humidity, etc 352 (Ren et al.,2018; Wang et al.,2019). Besides, urban vegetation amount is relatively small 353 compared with natural vegetation.

354 Undeniably, there exist some limitations for our research. It should be noted that PET 
355 intensity was obtained by only three years (1990, 2005, and 2015) for summer in our research.

356 The PET in more continuous years should be used to conduct the spatiotemporal change patterns

357 of urban thermal environment.In addition, PET might not change significantly in cities over

358 years, especially when averaged into a single season Our study did not capture the severity of

359 urban thermal discomfort and neither its peaks, and the averaged PET for a summer season might

360 only provide a general condition for each city in each year. Therefore, more temporal studies

361 should be conducted to explore the daily variation of PET in the future to reveal some more

362 detailed information about PET(Ren et al.,2018). Besides, the correlation analyses conducted in

363 different regions may lead to different results according to previous studies(Lin et al.,2018; Cao

364 et al.,2018; Sun et al.,2019;). Therefore, there are some limitations existing in the correlation

365 analyses across different regions. For comprehensive understanding relationships between PET

366 and drivers, it is necessary to analyze the relationships across different regions. However, if we

367 would like to accurately identify the associated drivers and mitigation strategies of PET in single

368 city, it is better to analyze the relationships between PET and its drivers across many continuous 369 years.

370 Given the general circumstance of global climate warming, the frequency and intensity of 371 urban heat events would increase, especially in developing countries such as China ( Sun et 372 al.,2019) and urban thermal environment could be deteriorated in the future. Our study presented 373 here will have some great management implications with many benefits to the urban planning, 374 healthcare organizations and the power sector. Existing research has showed that the increase of 375 urban air temperature could result in more usage of electricity (Akbari, Pomerantz, \& Taha, 2001; 376 Limones-Rodriguez et al.,2018). Our study results could provide the basic information 377 associated with the urban thermal environment to city power agencies. The spatiotemporal 378 patterns of summer PET intensity could help the power agencies get the power demand 379 variability at different cities. In addtion, many cities are aggressively taking some measures such 380 as cool/green roofs and urban greening to reduce the urban heat island phenomena and moderate 381 urban thermal environment (e.g., Akbari, Konopacki, \& Pomerantz,1999; Lai et al.,2019). 
382 Information on monthly and seasonal changes of urban thermal comfort could help these 383 governmental agencies quantify the potential benefits of various adaptation strategies.

\section{Conclusions}

Rapid urbanization has a great impact on urban thermal environment. In this study, we cities in China over the past 25 years and attempted to explore relationships between urbanization variables and urban thermal comfort. By this study, several conclusions may be derived from our experimental results as follows:

(1) Urban thermal environment and comfort has changed greatly during the 25 years and the changes of urban climate in different regions are inconsistent.

(2) From 1990 to 2015, the PET of most cities (81\%) in China exhibited an increasing

394

395

396

397

398

399

400

401

402

403

404

405

406

407

change, especially in North region $\left(4^{\circ} \mathrm{C}\right)$, followed by Northeast region $\left(3.4^{\circ} \mathrm{C}\right)$. From 2005 to 2015, the PET in some cities in China began to exhibit decreasing changes. However, there are still $33 \%$ of cities that had positive trends, mostly occurring in North region in China.

(3) Urbanization has a significant influence on urban climate and five of the seven urbanization variables presented significant positive effects on PET except for population density. The most important contribution to changes in thermal comfort is GDP, followed by urban population.

Changes in urban thermal environment caused by urbanization need to be emphasized seriously, especially the cities in the Northeast and North region in China. Our results may help researchers and city planners to well understand PET formation and provide practical guidelines, such as, reasonable planning for an unbalanced regional development of industries for urban planners to improve urban thermal environment. .

\section{Acknowledgements}

This research was supported by Youth Science fund project (41701210) sponsored by the National Natural Science Foundation of China and Science Development Project of Jilin 
408 Province, China (20180418138FG). We would like also to provide our great gratitude to the 409 editors and the anonymous reviewers who gave us their insightful comments and suggestions.

410

411

412

413

414

415

416

417

418

419

420

421

422

423

424

425

426

427

428

429

430

431

432

433

\section{References}

Aljawabra, F, Nikolopoulou, M (2018) Thermal comfort in urban spaces: a cross-cultural study in the hot arid climate. International Journal of Biometeorology 62:1901-1909.

Alo, C, Wang, G, (2010) Role of dynamic vegetation in regional climate predictions over western Africa. Climate Dynamics 35: 907-922.

Anup, K C, Whale, J, Urmee, T (2019) Urban wind conditions and small wind turbines in the built environment: A review. Renewable Energy 131:268-283.

Basu, R, Samet, J M (2002) Relation between elevated ambient temperature and mortality: A review of the epidemiologic evidence. Epidemiologic Reviews 24:190-202.

Cao, Q, Yu, D, Georgescu, M, Wu, J, Wang, W (2018) Impacts of future urban expansion on summer climate and heat-related human health in eastern China. Environment International 112:134-146.

Cao, X, Onishi, A, Chen, J, Imura, H (2010) Quantifying the cool island intensity of urban parks using ASTER and IKONOS data. Landscape and Urban Planning 96:224-231.

Cheung, P K, Jim, C Y (2018) Subjective outdoor thermal comfort and urban green space usage in humid-subtropical Hong Kong. Energy and Buildings 173:150-162.

Chen, L, Ma, Z, Zhao, T, (2017) Modeling and analysis of the potential impacts on regional climate due to vegetation degradation over arid and semi-arid regions of China. Climatic Change 144: 461-473.

Froehlich, D, Matzarakis, A (2018). Spatial Estimation of Thermal Indices in Urban AreasBasics of the SkyHelios Model. Atmosphere 9:1-6.

Fu, P, Weng, Q (2018) Variability in annual temperature cycle in the urban areas of the United States as revealed by MODIS imagery. Isprs Journal of Photogrammetry and Remote Sensing 146:65-73. 
434 Galagoda, R U, Jayasinghe, G Y, Halwatura, R U, Rupasinghe, H T (2018) The impact of urban 435 green infrastructure as a sustainable approach towards tropical micro-climatic changes and 436 human thermal comfort. Urban Forestry \& Urban Greening 34:1-9.

437 Geall, S, Ely, A (2018) Narratives and Pathways towards an Ecological Civilization in 438 Contemporary China. China Quarterly 236:1175-1196.

439 Giridharan, R, Emmanuel, R (2018) The impact of urban compactness, comfort strategies and 440 energy consumption on tropical urban heat island intensity: A review. Sustainable Cities $441 \quad$ and Society 40:677-687.

442 Han, S, Tang, Q, Xu, D (2019) Impacts of urbanization and agricultural development on 443 observed changes in surface air temperature over mainland China from 1961 to 2006. $444 \quad$ Theoretical and Applied Climatology 135: 3-4.

445 Hernandez-Moreno, A, Reyes-Paecke, S (2018) The effects of urban expansion on green 446 infrastructure along an extended latitudinal gradient (23 degrees S-45 degrees S) in Chile 447 over the last thirty years. Land Use Policy 79:725-733.

448 Huang, J, Zhou, C, Zhuo, Y, Xu, L, Jiang, Y (2016) Outdoor thermal environments and activities 449 in open space: An experiment study in humid subtropical climates. Building and $450 \quad$ Environment 103:238-249.

451 Jiang, S, Hua, H, Sheng, H, Jarvie, H P, Liu, X, Zhang, Y, Yuan, Z, Zhang, L, Liu, X (2019) 452 Phosphorus footprint in China over the 1961-2050 period: Historical perspective and future 453 454 455

Lai, D, Liu, W, Gan, T, Liu, K, Chen, Q (2019) A review of mitigating strategies to improve the 459 thermal environment and thermal comfort in urban outdoor spaces. The Science of the total 460 prospect. Science of the Total Environment 650:687-695.

Klenk, J, Becker, C, Rapp, K (2010) Heat-related mortality in residents of nursing homes. Age and Ageing 39:245-252.

Kolokotroni, M, Zhang, Y, Watkins, R (2007) The London Heat Island and building cooling design. Solar Energy 81:102-110. environment 661:337-353. 
461 Lan, Y, Zhan, Q (2017) How do urban buildings impact summer air temperature? The effects of 462 building configurations in space and time. Building and Environment 125:88-98.

463 Lee, H, Mayer, H (2018) Thermal comfort of pedestrians in an urban street canyon is affected by 464 increasing albedo of building walls. International Journal of Biometeorology 62:1199-1209.

465

466

467

468

469

470

471

472

473

474

475

476

477

478

479

480

481

482

483

484

485

486

487
Li, L, Zha, Y,(2018) Mapping relative humidity, average and extreme temperature in hot summer over China. Science of the Total Environment 615: 875-881.

Limones-Rodriguez, N, Marzo-Artigas, J, Fernanda Pita-Lopez, M, Pilar Diaz-Cuevas, M (2018) The impact of climate change on air conditioning requirements in Andalusia at a detailed scale. Theoretical and Applied Climatology 134:1047-1063.

Lin, L, Ge, E, Liu, X, Liao, W, Luo, M (2018a). Urbanization effects on heat waves in Fujian Province, Southeast China. Atmospheric Research 210:123-132.

Lin, Y, Jim, C Y, Deng, J, Wang, Z (2018b) Urbanization effect on spatiotemporal thermal patterns and changes in Hangzhou (China). Building and Environment 145:166-176.

Linden, J, Fonti, P, Esper, J (2016) Temporal variations in microclimate cooling induced by urban trees in Mainz, Germany. Urban Forestry \& Urban Greening 20:198-209.

Liu, C, Chen, L, Vanderbeck, R M, Valentine, G, Zhang, M, Diprose, K, McQuaid, K (2018) A Chinese route to sustainability: Postsocialist transitions and the construction of ecological civilization. Sustainable Development 26:741-748.

Liu, Z, Liu, Y, He, B-J, Xu, W, Jin, G, Zhang, X (2019) Application and suitability analysis of the key technologies in nearly zero energy buildings in China. Renewable \& Sustainable Energy Reviews 101:329-345.

Liu, Q, Peng, Pei, Wang, Y (2019) Microclimate regulation efficiency of the rural homegarden agroforestry system in the Western Sichuan Plain, China. Journal of Mountain Science 16: 516-528.

Lu, X, Lin, C, Li, W, Chen, Y, Huang, Y, Fung, J C H, Lau, A K H (2019) Analysis of the adverse health effects of PM2.5 from 2001 to 2017 in China and the role of urbanization in aggravating the health burden. Science of the Total Environment 652:683-695.

Peer) reviewing PDF | (2019:04:36787:1:2:NEW 21 Jun 2019) 
488

489

490

491

492

493

494

495

496

497

498

499

500

501

502

503

504

505

506

507

508

509

510

511

512

513

514

Ma, M, Cai, W, Wu, Y, 2019. China Act on the Energy Efficiency of Civil Buildings (2008) A decade review. Science of the Total Environment 651:42-60.

Mahmoud, S H, Gan, T Y (2018) Long-term impact of rapid urbanization on urban climate and human thermal comfort in hot-arid environment. Building and Environment 142:83-100.

Matzarakis, A, Mayer, H, Iziomon, M G (1999) Applications of a universal thermal index: physiological equivalent temperature. International Journal of Biometeorology 43:76-84.

Matzarakis, A, Rammelberg, J, Junk, J (2013) Assessment of thermal bioclimate and tourism climate potential for central Europe-the example of Luxembourg. Theoretical and Applied Climatology 114:193-202.

Montgomery, M (2017) Population Growth and Rapid Urbanization in the Developing World. Population and Development Review 43:176-177.

Moustris, K, Tsiros, I X, Tseliou, A, Nastos, P (2018) Development and application of artificial neural network models to estimate values of a complex human thermal comfort index associated with urban heat and cool island patterns using air temperature data from a standard meteorological station. International Journal of Biometeorology 62:1265-1274.

Oxoli, D, Ronchetti, G, Minghini, M, Molinari, M E, Lotfian, M, Sona, G, Brovelli, M A (2018) Measuring Urban Land Cover Influence on Air Temperature through Multiple Geo-DataThe Case of Milan, Italy. Isprs International Journal of Geo-Information 7.

Pan, S-Y, Gao, M, Shah, K J, Zheng, J, Pei, S-L, Chiang, P-C (2019) Establishment of enhanced geothermal energy utilization plans: Barriers and strategies. Renewable Energy 132:19-32.

Peng, J, Ma, J, Liu, Q, Liu, Y, Hua, Y, Li, Y, (2018) Spatial-temporal change of land surface temperature across 285 cities in China: An urban-rural contrast perspective. Science of the Total Environment 635:487-497.

Potchter, O, Cohen, P, Lin, T-P, Matzarakis, A (2018) Outdoor human thermal perception in various climates: A comprehensive review of approaches, methods and quantification. Science of the Total Environment 631-632:390-406.

Ren, Z, He, X, Pu, R,(2018)The impact of urban forest structure and its spatial location on urban 
cool island intensity.Urban Ecosystems 21: 863-874.

516 Sagris, V, Sepp, M (2017) Landsat-8 TIRS Data for Assessing Urban Heat Island Effect and Its

517 Impact on Human Health. Ieee Geoscience and Remote Sensing Letters 14:2385-2389.

518 Salata, F, Golasi, I, Ciancio, V, Rosso, F (2018) Dressed for the season: Clothing and outdoor 519 thermal comfort in the Mediterranean population. Building and Environment 146:50-63.

520 Salata, F, Golasi, L, Petitti, D, Vollaro, E d L, Coppi, M, Vollaro, A d L (2017) Relating 521 microclimate, human thermal comfort and health during heat waves: An analysis of heat island mitigation strategies through a case study in an urban outdoor environment. Sustainable Cities and Society 30:79-96.

Sarrat, C, Lemonsu, A, Masson, V, Guedalia, D (2006) Impact of urban heat island on regional atmospheric pollution. Atmospheric Environment 40:1743-1758.

Shi, F, Weaver, D, Zhao, Y, Huang, M-F, Tang, C, Liu, Y (2019) Toward an ecological civilization: Mass comprehensive ecotourism indications among domestic visitors to a Chinese wetland protected area. Tourism Management 70:59-68.

Sun, R, Lu, Y, Yang, X, Chen, L (2019) Understanding the variability of urban heat islands from local background climate and urbanization. Journal of Cleaner Production 208:743-752.

Sun, X, Crittenden, J C, Li, F, Lu, Z, Dou, X (2018) Urban expansion simulation and the spatiotemporal changes of ecosystem services, a case study in Atlanta Metropolitan area, USA. Science of the Total Environment 622:974-987.

Sun, Q, Miao, C, Hanel, M, Borthwick, A. G, Duan, Q, Ji, D, \& Li, H (2019). Global heat stress on health, wildfires, and agricultural crops under different levels of climate warming. Environment international 128: 125-136.

Szabo, C P (2018) Urbanization and mental health: a developing world perspective. Current Opinion in Psychiatry 31:256-257.

Tarabon, S, Bertrand, R, Lavoie, C, Vigouroux, T, Isselin-Nondedeu, F (2018) The effects of climate warming and urbanised areas on the future distribution of Cortaderia selloana, pampas grass, in France. Weed Research 58:413-423. 
542 Wang, K, Li, Y, Luo, Z, Yin, S, Chan, P W (2018) Harmonic analysis of 130-year hourly air 543 temperature in Hong Kong: detecting urban warming from the perspective of annual and 544 daily cycles. Climate Dynamics 51:613-625.

545 Wang, Y, Chen, L, Song, Z, Huang, Z, Ge, E, Lin, L, Luo, M (2019) Human-perceived 546 temperature changes over South China: Long-term trends and urbanization effects. $547 \quad$ Atmospheric Research 215:116-127.

548 Wang, W, Zhang, B, Zhou, W, (2019)The effect of urbanization gradients and forest types on microclimatic regulation by trees, in association with climate, tree sizes and species compositions in Harbin city, northeastern China. Urban Ecosystems 22: 367-384.

Weng, Q, Liu, H, Lu, D (2007) Assessing the effects of land use and land cover patterns on thermal conditions using landscape metrics in city of Indianapolis, United States. Urban Ecosystems 10:203-219.

Weng, Q, Yang, S (2006) Urban air pollution patterns, land use, and thermal landscape: An 555 examination of the linkage using GIS. Environmental Monitoring and Assessment 117:463489.

Wong, L P, Alias, H, Aghamohammadi, N, Aghazadeh, S, Sulaiman, N M N (2018) Physical,

$\mathrm{Xu}, \mathrm{M}$, Hong, B, Mi, J, Yan, S (2018) Outdoor thermal comfort in an urban park during winter in cold regions of China. Sustainable Cities and Society 43:208-220.

Yang, Q, Huang, X, Tang, Q (2019) The footprint of urban heat island effect in 302 Chinese 

662.

571 Yang, W, Lin, Y, Li, C-Q (2018) Effects of Landscape Design on Urban Microclimate and 572 Thermal Comfort in Tropical Climate. Advances in Meteorology. 28:1-13

Yang, X, Yao, L,Peng, LH (2019) Evaluation of a diagnostic equation for the daily maximum urban heat island intensity and its application to building energy simulations. Energy and Buildings 193: 160-173.

Yao, R, Wang, L, Huang, X, Niu, Z, Liu, F, Wang, Q, (2017)Temporal trends of surface urban heat islands and associated determinants in major Chinese cities. Science of the Total Environment 609:742-754.

Zhang, Y, Sun, L (2019) Spatial-temporal impacts of urban land use land cover on land surface temperature: Case studies of two Canadian urban areas. International Journal of Applied Earth Observation and Geoinformation 75:171-181.

Zhao, D, Wu, S, (2014) Responses of vegetation distribution to climate change in China. Theoretical and Applied Climatology 117: 15-28.

Zhao, J, Chen, S, Jiang, B, Ren, Y, Wang, H, Vause, J, Yu, H, (2013) Temporal trend of green space coverage in China and its relationship with urbanization over the last two decades. Science of the Total Environment 442: 455-465

Zhang, Z, Lin, B (2019) Energy Conservation and Emission Reduction of Chinese Cement Industry: From a Perspective of Factor Substitutions. Emerging Markets Finance and Trade 55:967-979.

Zhou, Z, Deng, Q, Yang, G, Lin, Y (2018) Quantitative Study of Using Piloti for Passive 
Figure 1

Spatial distribution of 180 cities in China

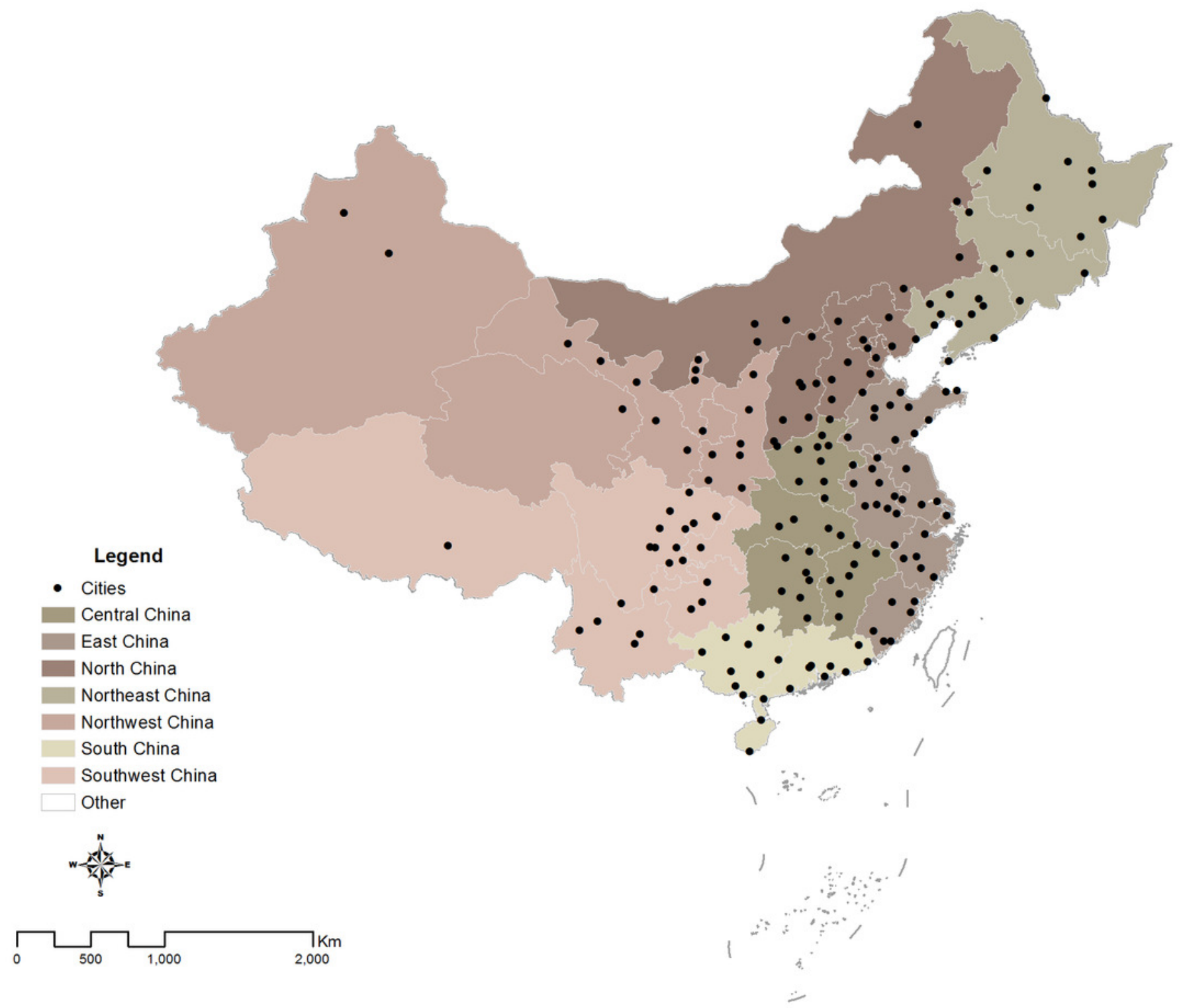


Figure 2

Changes of urban thermal parameters across different regions in China

Fig. 2. Changes of urban thermal parameters across different regions in China

(NE:Northeast, N:North, NW:Northwest, C:Central, S:South, SW:Southwest and E:East)(A: Air temperature, B: Relative humidity,C:Wind speed). 

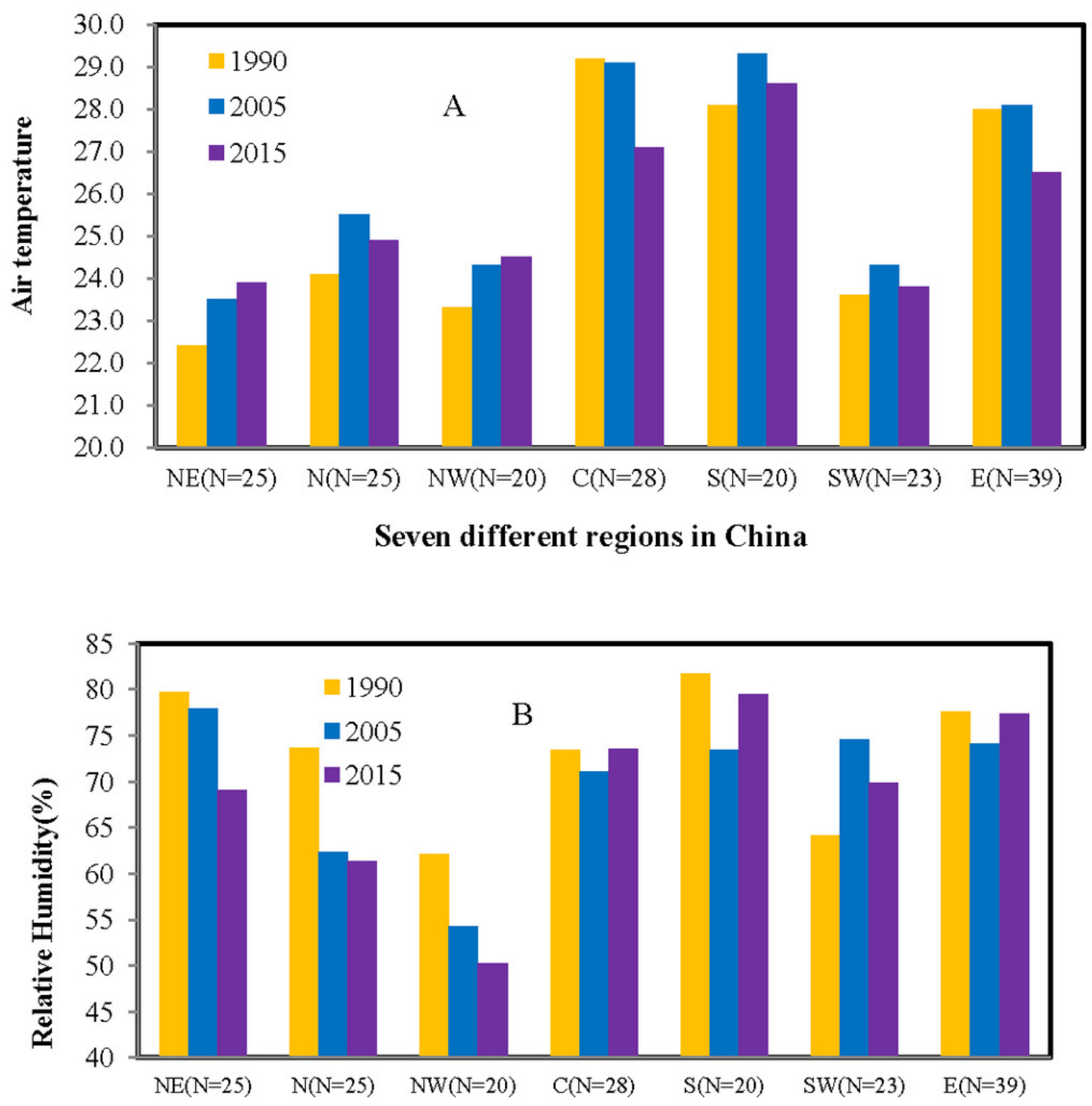

Seven different regions in China

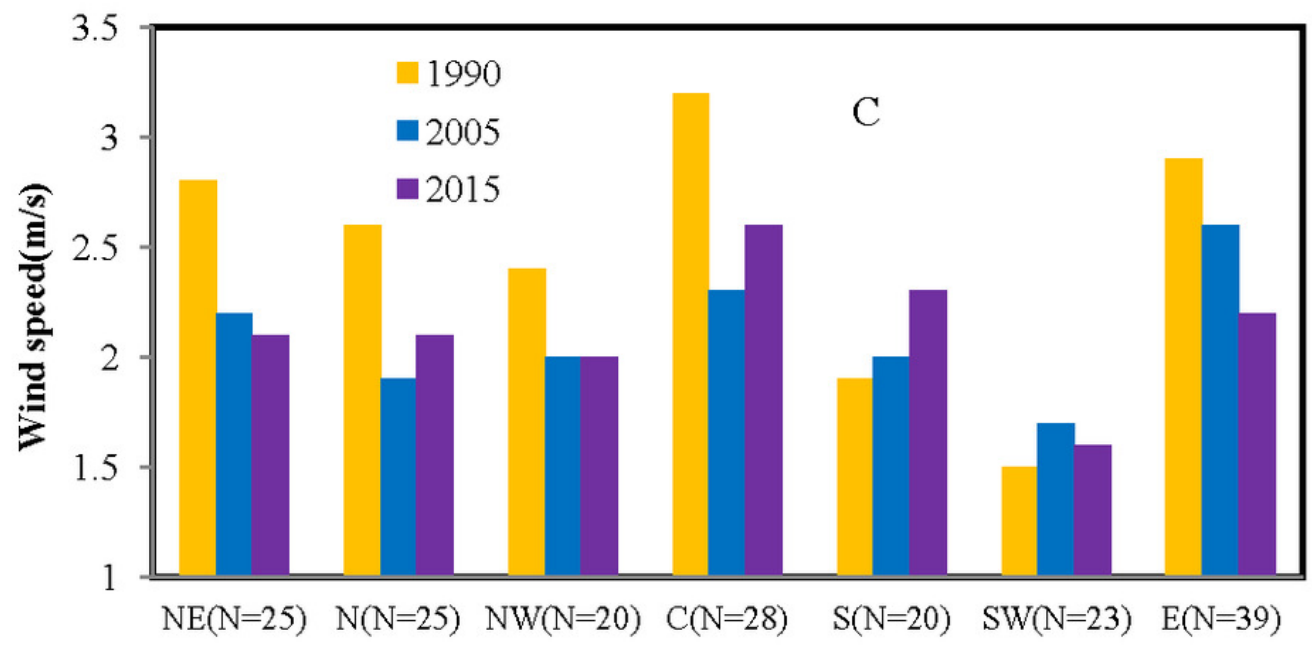

Seven different regions in China 
Figure 3

Spatial pattern of PET across different regions in China

Fig. 3. Spatial pattern of PET across different regions in China (A: PET in 1990, B:PET in 2005,C: PET in 2015). <!--W]\{ T-->
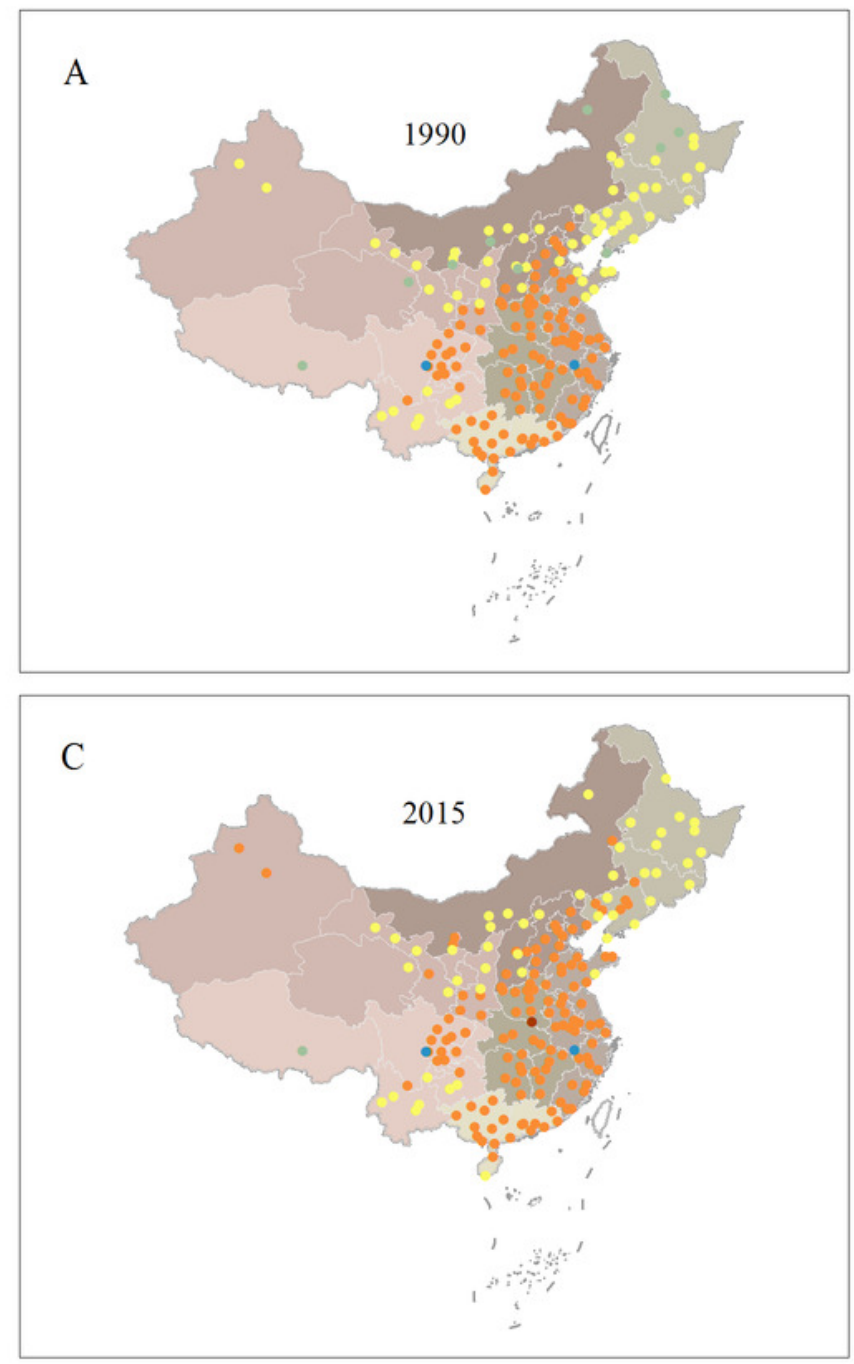
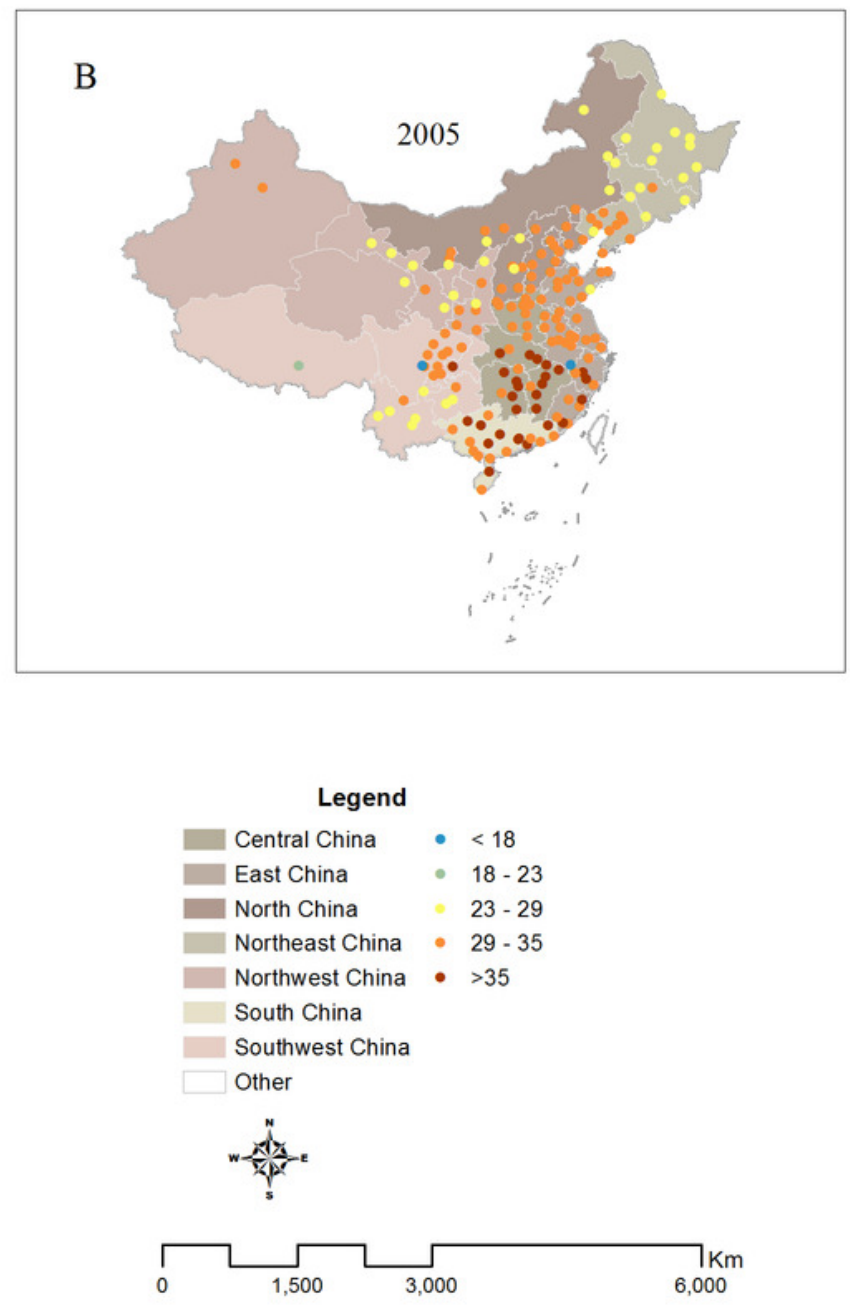
Figure 4

Histogram of the frequency statistics for PET

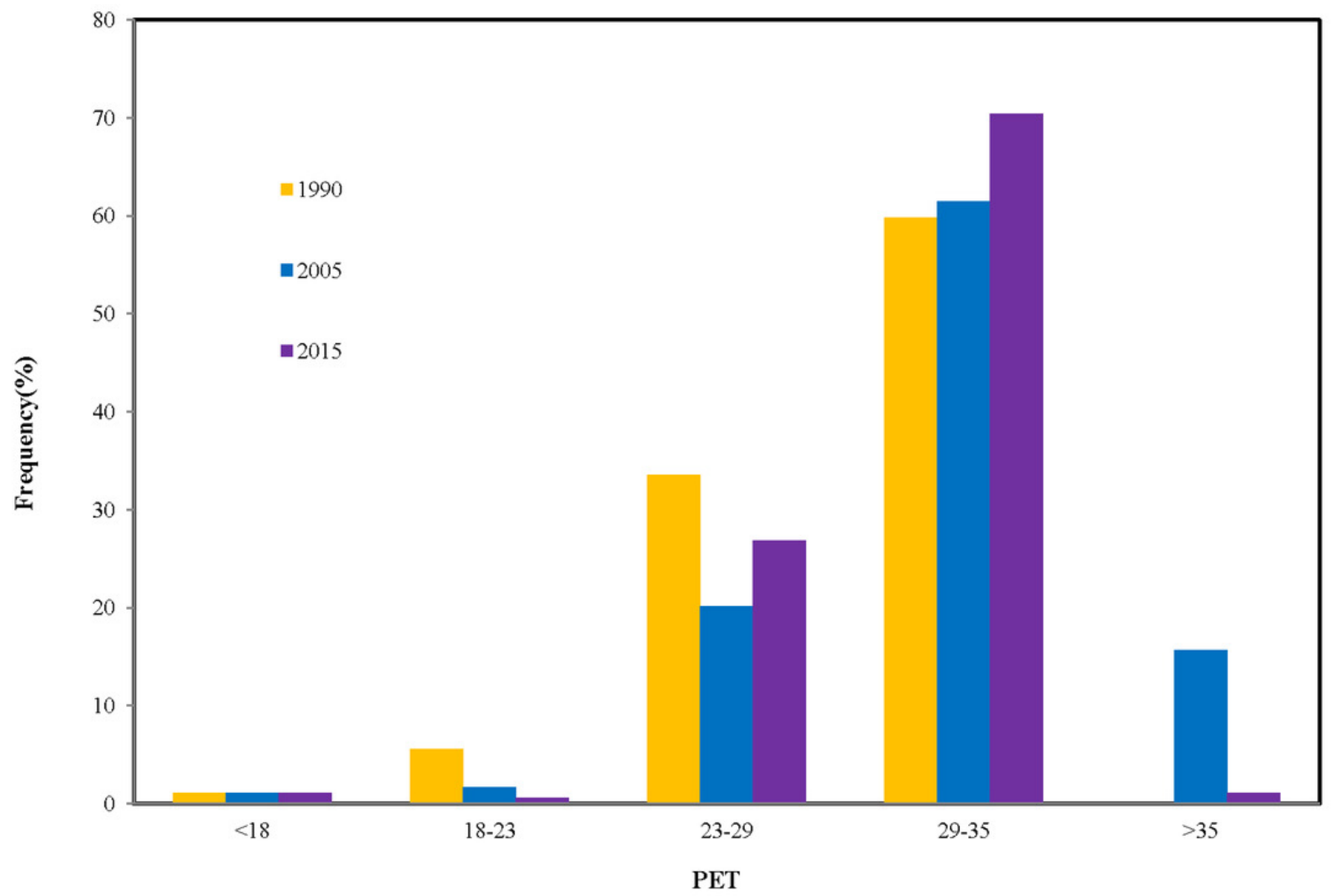


Figure 5

Spatial patterns of PET changes in different time periods and regions in China

Fig. 5 Spatial patterns of PET changes in different time periods and regions in China(A: PET from 1990 to 2005,B: PET from 2005 to 2015,C: PET from 1990 to 2015).
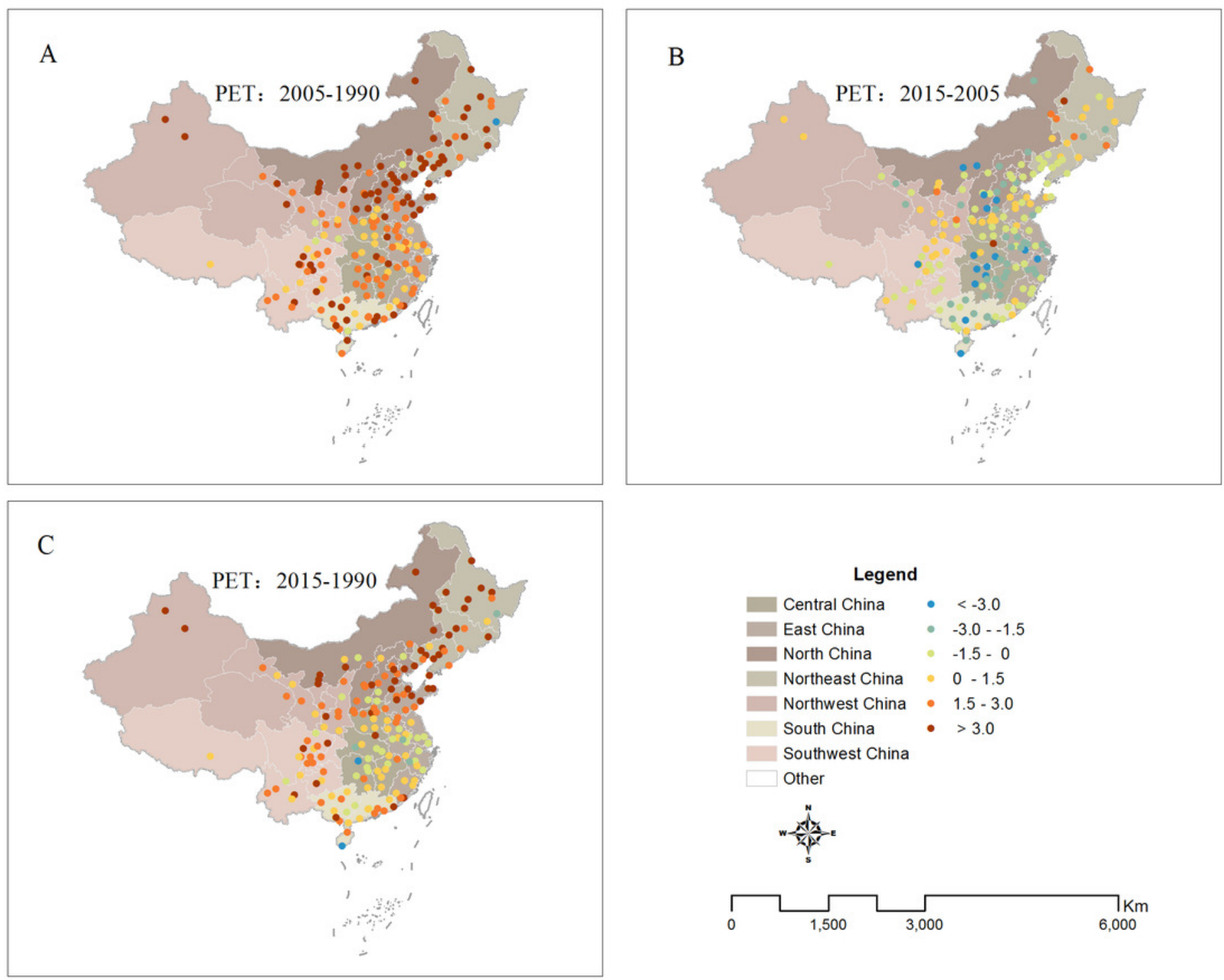
Figure 6

Histogram of the frequency statistics for PET changes across different years

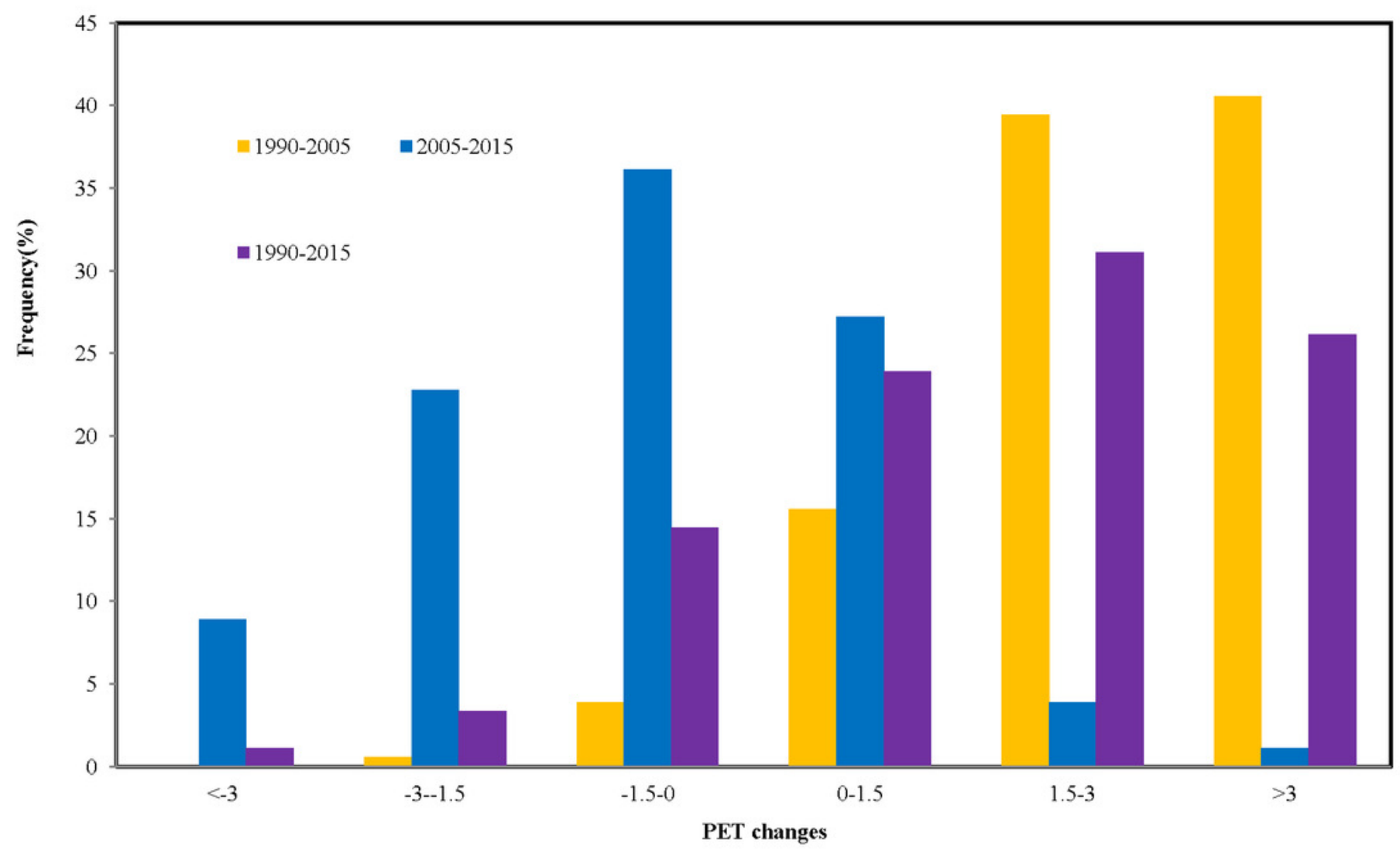


Figure 7

Regression analyses of urbanization with PET

Fig. 7. Regression analyses of urbanization with PET $(n=540)$ (A:Population in Build-up area,B:Total population, C:Build-up area,D:Population density,E: GDP,F:Per capita GDP, G: Urban vegetaion coverage). 

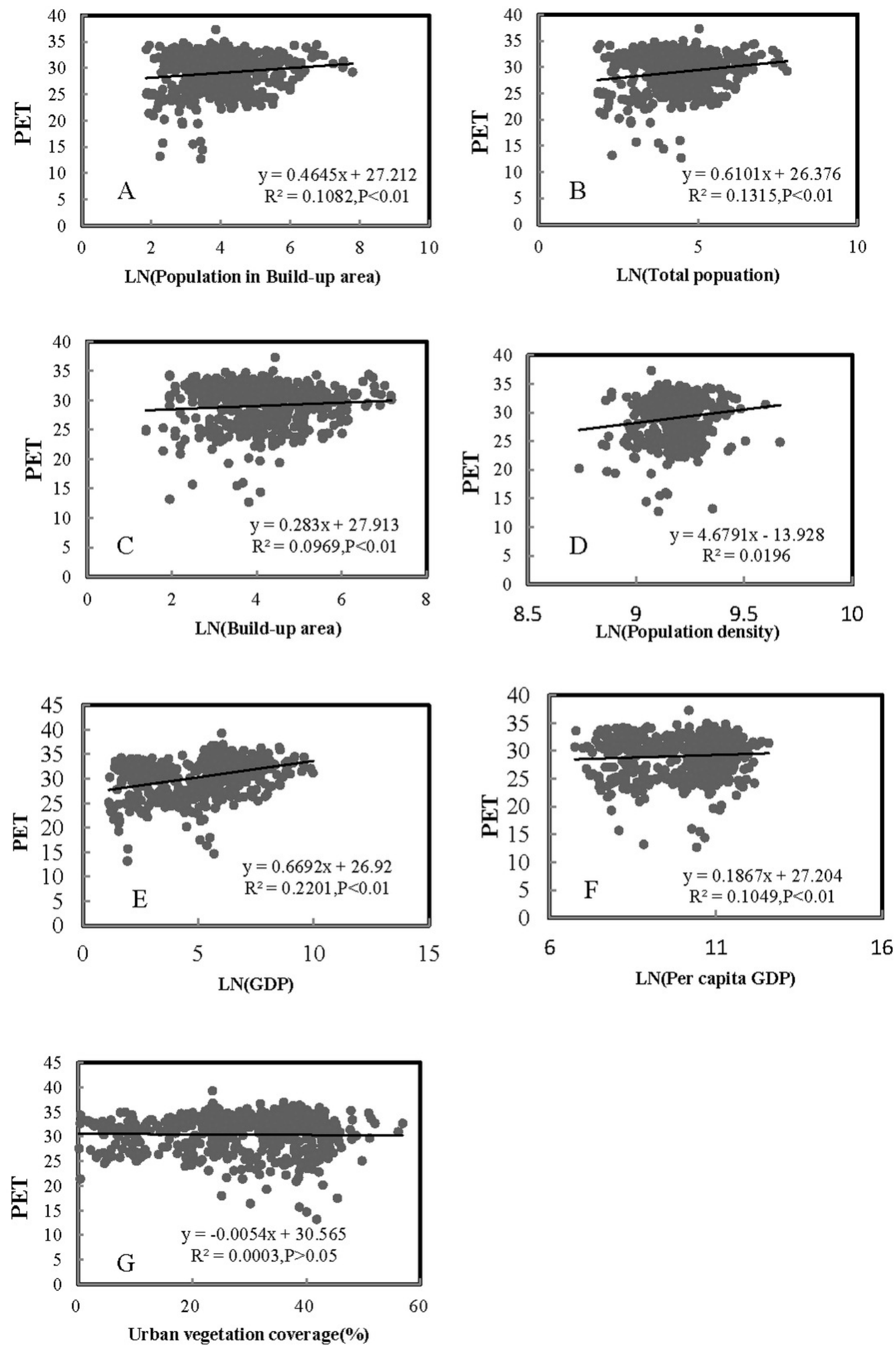


\section{Table $\mathbf{1}$ (on next page)}

The average urban climte in 1990, 2005, 2015, 1990s, 2000s, and 2010s in China

The average urban climte in 1990, 2005, 2015, 1990s, 2000s, and 2010s in China 
1

2

3

4

\begin{tabular}{lcccccr}
\hline Urban climate & 1990 & 2005 & 2015 & $1990 \mathrm{~s}$ & $2000 \mathrm{~s}$ & $2010 \mathrm{~s}$ \\
\hline Temperature $\left({ }^{\circ} \mathrm{C}\right)$ & 25.3 & 26.8 & 26.1 & 24.9 & 27.1 & 25.8 \\
Humidity $(\%)$ & 75.8 & 70.4 & 68.3 & 75.13 & 71.3 & 67.7 \\
Wind speed(m/s) & 3.1 & 2.1 & 2.3 & 2.8 & 1.9 & 2 \\
Solar radia $\left(\mathrm{W} / \mathrm{m}^{2}\right)$ & 393.4 & 389.5 & 401.2 & 390.5 & 386.7 & 398.5 \\
\hline
\end{tabular}

6

Table. 1. The average urban climte in 1990, 2005, 2015, 1990s, 2000s, and 2010s in China

4 
Table 2 (on next page)

Thermal sensation classes for human beings 
1

2

3

Table. 2. Thermal sensation classes for human beings.

\begin{tabular}{lll}
\hline PET $\left({ }^{\circ} \mathrm{C}\right)$ & Thermal Perception & Grade of physical stress \\
\hline$>42$ & Very hot & Extreme heat stress \\
$35-42$ & Hot & Strong heat stress \\
$29-35$ & Warm & Moderate heat stress \\
$23-29$ & Slightly warm & Slight heat stress \\
$18-23$ & Comfortable & No thermal stress \\
$13-18$ & Slightly cool & Slight cold stress \\
\hline
\end{tabular}

4 


\section{Table 3 (on next page)}

The statistical description of urbanization and meteorological parameters in China 
1

2

3

4 Table. 3. The statistical description of urbanization and meteorological parameters in China.

\begin{tabular}{lccc}
\hline Urbanization and urban climate & 1990 & 2005 & 2015 \\
\hline urban vegetation cover(\%) & $17.9 \mathrm{a}$ & $32.2 \mathrm{~b}$ & $38.8 \mathrm{c}$ \\
Urban population $\left(10^{4}\right)$ & $58.4 \mathrm{a}$ & $118.9 \mathrm{~b}$ & $136.6 \mathrm{c}$ \\
Built-up area $\left(\mathrm{km}^{2}\right)$ & $45.4 \mathrm{a}$ & $117.9 \mathrm{~b}$ & $160.2 \mathrm{c}$ \\
Population density $\left(\mathrm{n} / \mathrm{km}^{2}\right)$ & $12013.3 \mathrm{c}$ & $9629.8 \mathrm{~b}$ & $7777.9 \mathrm{a}$ \\
GDP & $38.3 \mathrm{a}$ & $785.7 \mathrm{~b}$ & $1583.9 \mathrm{c}$ \\
Per capita GDP & $5806.9 \mathrm{a}$ & $53105.7 \mathrm{~b}$ & $68682.6 \mathrm{c}$ \\
Temperature $\left({ }^{\circ} \mathrm{C}\right)$ & $25.3 \mathrm{a}$ & $26.8 \mathrm{~b}$ & $26.1 \mathrm{~b}$ \\
Humidity $(\%)$ & $75.8 \mathrm{a}$ & $70.4 \mathrm{~b}$ & $68.3 \mathrm{c}$ \\
Wind speed $(\mathrm{m} / \mathrm{s})$ & $3.1 \mathrm{a}$ & $2.1 \mathrm{~b}$ & $2.3 \mathrm{~b}$ \\
Solar radia $\left(\mathrm{W} / \mathrm{m}^{2}\right)$ & $393.4 \mathrm{a}$ & $389.5 \mathrm{a}$ & $401.2 \mathrm{a}$ \\
\hline
\end{tabular}

5 Values with different letters indicate statistically significant differences among the three different years at $\mathrm{P}$-value $<0.05$

6

7 
Table 4(on next page)

Descriptive statistics of PET for 180 cities in China 
1

2

3

4

5

\begin{tabular}{llll}
\hline Year & 1990 & 2005 & 2015 \\
\hline Min & $13.2^{\circ} \mathrm{C}$ & $17.5^{\circ} \mathrm{C}$ & $14.7^{\circ} \mathrm{C}$ \\
Max & $34.3^{\circ} \mathrm{C}$ & $37^{\circ} \mathrm{C}$ & $39.3^{\circ} \mathrm{C}$ \\
Average & $28.7^{\circ} \mathrm{C}$ & $31.7^{\circ} \mathrm{C}$ & $30.6^{\circ} \mathrm{C}$ \\
SD & $3.9^{\circ} \mathrm{C}$ & $3.4^{\circ} \mathrm{C}$ & $3.3^{\circ} \mathrm{C}$ \\
\hline
\end{tabular}

7

8

9

10

11

12

13

14

Table. 4. Descriptive statistics of PET for 180 cities in China.

7

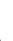

13 


\section{Table 5 (on next page)}

Pearson correlation coefficients between PET and urbanization 
1

2

3

4

\begin{tabular}{lc}
\hline Urbanizaiton indices & $\begin{array}{c}\text { Pearson } \\
\text { coefficients }\end{array}$ \\
\hline Total urban population & $0.136^{* *}$ \\
Urban population in build-up area & $0.182^{* *}$ \\
Built-up area(km2) & $0.164^{* *}$ \\
Population density $(\mathrm{n} / \mathrm{km} 2)$ & 0.022 \\
GDP(108 Yuan) & $0.168^{* *}$ \\
Per capita GDP(Yuan/person) & $0.234^{* *}$ \\
Urban vegetaion coverage $(\%)$. & -0.018 \\
\hline
\end{tabular}

5

** Correlation is statistically significant at the 0.01 level (two-tailed).

6

7

8

9

10

11

12

13

14

15 


\section{Table 6(on next page)}

Summary of the multiple regression models, in which PET is a response variable, and urbanization variables are predictors 
1

2

3

4 Table 6. Summary of the multiple regression models, in which PET is a response variable, 5 and urbanization variables are predictors

\begin{tabular}{llllll}
\hline Variable & Lable & Cofficient & Std Coeffcient & $\mathrm{t}$ & $\mathrm{p}$ \\
\hline Constant & & 25.759 & 0 & 32.667 & $<0.001$ \\
GDP & $\mathrm{b} 1$ & 1.265 & 0.655 & 8.443 & $<0.001$ \\
BA & $\mathrm{b} 2$ & -2.039 & -0.573 & -6.072 & $<0.001$ \\
TP & $\mathrm{b} 3$ & 1.104 & 0.307 & 3.842 & $<0.001$ \\
VS & $\mathrm{b} 4$ & 0.051 & 0.167 & 3.822 & $<0.001$ \\
\hline
\end{tabular}

7

8

9

10

11

12

13

14

15

16 